\title{
Experimentation of the Incineration of Paper Waste at the University Press of Ouagadougou (PUO)
}

\author{
Boureima KABORE ${ }^{1,3 \#}$ (D), Germain W. P. OUEDRAOGO ${ }^{2,3}$, Boureima YARBANGA ${ }^{3}$, Siè \\ $\mathrm{KAM}^{3}$, Dieudonné Joseph BATHIEBO ${ }^{3}$ \\ ${ }^{1}$ Laboratory of Research in Energetic and Space Meteorology, University Norbert ZONGO, \\ Koudougou, Burkina Faso \\ ${ }^{2}$ University of Fada N'Gourma, Fada N'Gourma, Burkina Faso \\ ${ }^{3}$ Laboratory of Renewable Thermal Energies, University Joseph KI-ZERBO, Ouagadougou, \\ Burkina Faso.
}

\#corresponding author

Type of Work: Peer Reviewed.

DOI: 10.21013/jas.v16.n4.p1

DOI URL: https://dx.doi.org/10.21013/jas.v16.n4.p1

\section{How to cite this paper:}

KABORE, B. et al. (2021). Experimentation of the Incineration of Paper Waste at the University Press of Ouagadougou (PUO). IRA-International Journal of Applied Sciences (ISSN 2455-4499), 16(4), 59-67. DOI: https://dx.doi.org/10.21013/jas.v16.n4.p1

(C) IRA Academico Research.

(c) B EY-Nc This work is licensed under a Creative Commons Attribution-NonCommercial
4.0 International License subject to a proper citation to the publication source of the work.

Disclaimer: The scholarly papers as reviewed and published by IRA Academico Research are the views and opinions of their respective authors and are not the views or opinions of IRA Academico Research. IRA Academico Research disclaims any harm or loss caused due to the published content to any party.

IRA Academico Research is an institutional publisher member of Publishers International Linking Association Inc. (PILA-CrossRef), USA. IRA Academico Research is an institutional signatory to the Budapest Open Access Initiative, Hungary advocating the open access of scientific and scholarly knowledge. IRA Academico Research is also a registered content provider under Open Access Initiative Protocol for Metadata Harvesting (OAI-PMH).

This paper is peer-reviewed under IRA Academico Research's Peer Review Program.

Boureima KABORE (D)/0000-0003-0757-6910 


\section{ABSTRACT}

Waste management and recycling is major problem in our developing countries for several reasons, including population growth. In Burkina Faso, various techniques for treating this garbage exist and among them, we can cite incineration. Incineration is a heat treatment of garbage that reduces the volume of the latter. This work relates to the experimental study of the incineration of paper waste from the incinerator of the University Press of Ouagadougou. The results of this study show that this device is very useful in that it allows the incineration of paper garbage produced by the printing press. It, therefore, has an environmental advantage because its use promotes better management of paper waste.

Keywords: Experimental study, Paper waste, Incineration, Incinerator

\section{Introduction}

The problem of waste management arises with the arrival of industrial production and the development of urban cities (a consequence of population growth). Indeed, not so long ago, almost anything could be recovered and organic compounds were recycled naturally [1]. The production of waste is the end of the economic cycle which includes the extraction of materials, their use in the production of goods and services, the consumption of the products and their end of life [2]. Household waste generates pollution and is the source of health risks that can come from two sources: the waste itself and the treatment of waste [3].

Today, the demands on consumer goods as well as the development of industry and synthetic chemicals have resulted in the creation of large quantities of ultimate waste. The elimination of this waste, therefore, requires new management approaches and ever more efficient treatment technologies that must take into account environmental concerns and sustainable development [4].

Incineration with energy recovery is a source of thermal energy that emits little greenhouse gas $\left(149 \mathrm{~g}\right.$ of $\mathrm{CO}_{2} /$ $\mathrm{kWh}$ ), far ahead of natural gas (206 g), LPG (231 g), heavy fuel oil (282 g) or charcoal (343 g) [5].

Currently, household waste management has become a priority problem in sub-Saharan Africa, mainly in urban regions which host an ever-increasing population and ever-increasing human activities. Burkina Faso is no exception to these realities. Its urban cities are currently undergoing strong demographic and spatial growth which has unfortunately not always been accompanied by the establishment of infrastructure and adequate waste management policy [6]. Incineration is a method of treating waste that involves burning it at high temperatures. It is also called heat treatment. It differs depending on whether or not there is energy recovery during combustion. Today, modern incinerators use the energy produced in the form of heat and/or electricity [7]. Incineration, like most waste treatments, aims to treat waste in such a way as to reduce its volume and hazards, while recovering (and therefore concentrating) or destroying potentially harmful substances. Incineration processes can also be a means of recovering the energy, mineral and or chemical content of the waste [7].

In this work, the aim is to study the temperature evolution of the combustion environment of an incinerator intended for the combustion of paper at the University Press of Ouagadougou (PUO).

\section{Presentation of the Incineration Furnace}

\subsection{Study Framework}

The University Press of Ouagadougou (PUO) located within the Joseph KI-ZERBO University, has a printing press that produces a large quantity of garbage on a daily basis, especially in cardboard and paper. Given the amount of waste produced by this printing plant, a treatment technique was adopted by the site managers.

This is how an incineration system was put in place. The role of this device is to incinerate the waste produced at this printing plant.

\subsection{Description of the Incinerator}

The following Figure 1 shows the Ouagadougou University Press incinerator. 


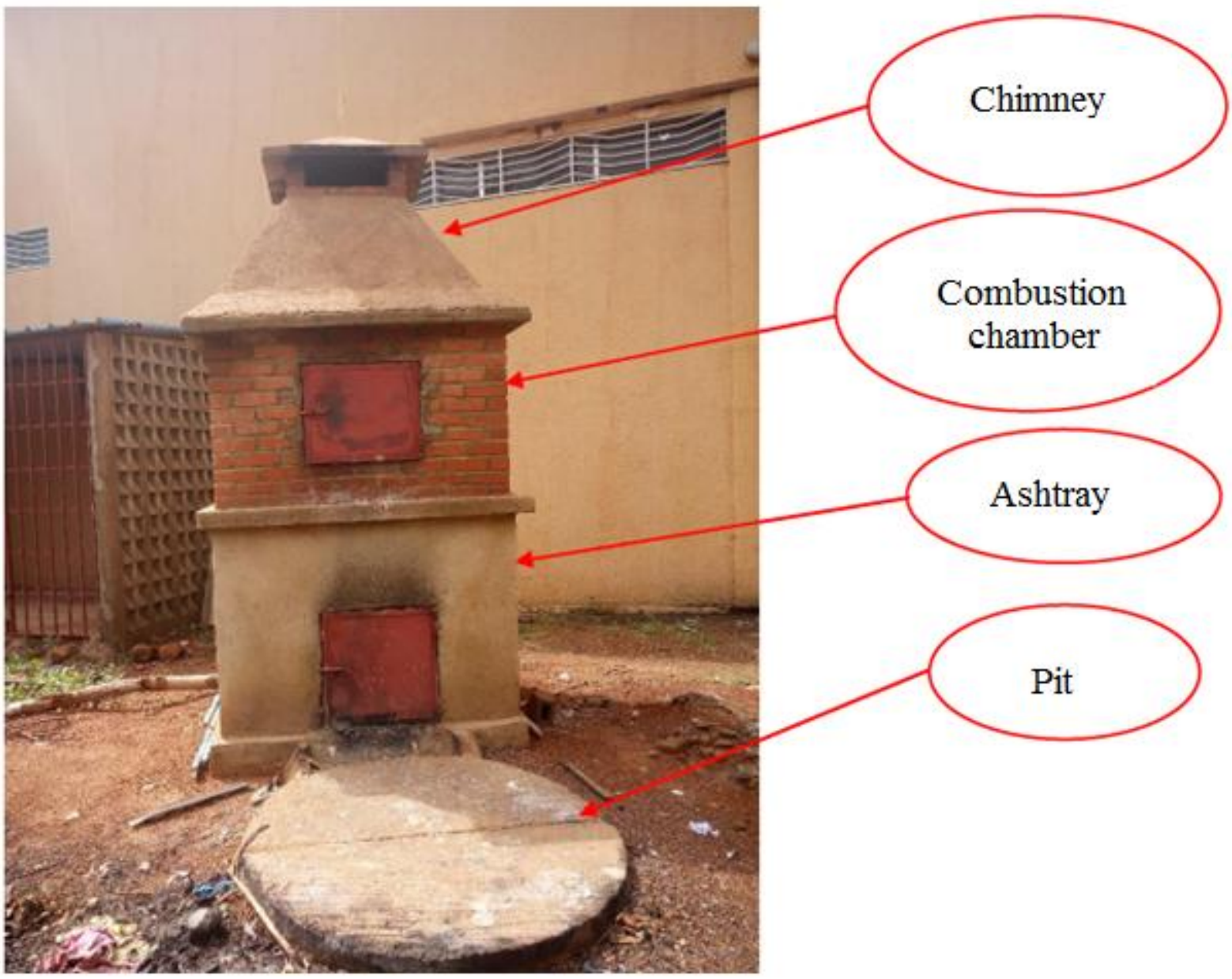

Figure 1: Incinerator at the University Press of Ouagadougou

The incinerator consists of a chimney, a combustion chamber with a volume of $1.54 \mathrm{~m}^{3}$ and an ashtray located under the combustion chamber grate (Figure 1). The walls of the combustion chamber are $5.6 \mathrm{~cm}$ thick and are made from terracotta bricks. The combustion chamber has two orifices located under the grate which allow combustion to be supplied with an oxidizer. The extraction of ashes and unburnt material takes place through the ashtray; these materials are then buried in a pit. The incinerator operates with natural convection.

\subsection{Phenomena Involved in Combustion}

Incineration involves a succession of physicochemical and thermal processes, some of which can take place simultaneously [8]: The fuel heats up, the energy input comes both from the radiation from the walls of the furnace and from the flames, from the convective exchange with the air in the enclosure and from the exchange by direct conduction of the solids in combustion. The moisture in the load vaporizes during this step, which is drying;

When the temperature of the waste is sufficient, the latter pyrolysis: the thermal decomposition of its organic fraction leads to the release of combustible gases (hydrocarbons, $\mathrm{CO}, \mathrm{H}_{2}$ ), chlorinated $(\mathrm{HCl})$, sulfur and nitrogen compounds (pyridine, pyrroles, amines)

And tars which can subsequently be cracked. If the temperature is high enough and there is oxygen, some of these gases will oxidize instantly. After pyrolysis, the solid is in the form of a carbon residue. This carbonaceous residue is in turn oxidized by $\mathrm{O}_{2}$, or gasified by $\mathrm{H}_{2} \mathrm{O}$ or $\mathrm{CO}_{2}$. These heterogeneous reactions complete the transformation of the combustible part of the waste, of which only ash remains.

Inert materials (minerals and metals), partially melted, in the form of oxides and salts, cool and form bottom ash which are residues from the combustion of coal or that of household waste. 


\section{Presentation of the Physical Model}

We used a decameter to measure the different parts of our incinerator shown in figure 2. From an axial symmetry, we get a cross-section. Figure 2 shows the diagram of the device in 3 Dimensions (3D).

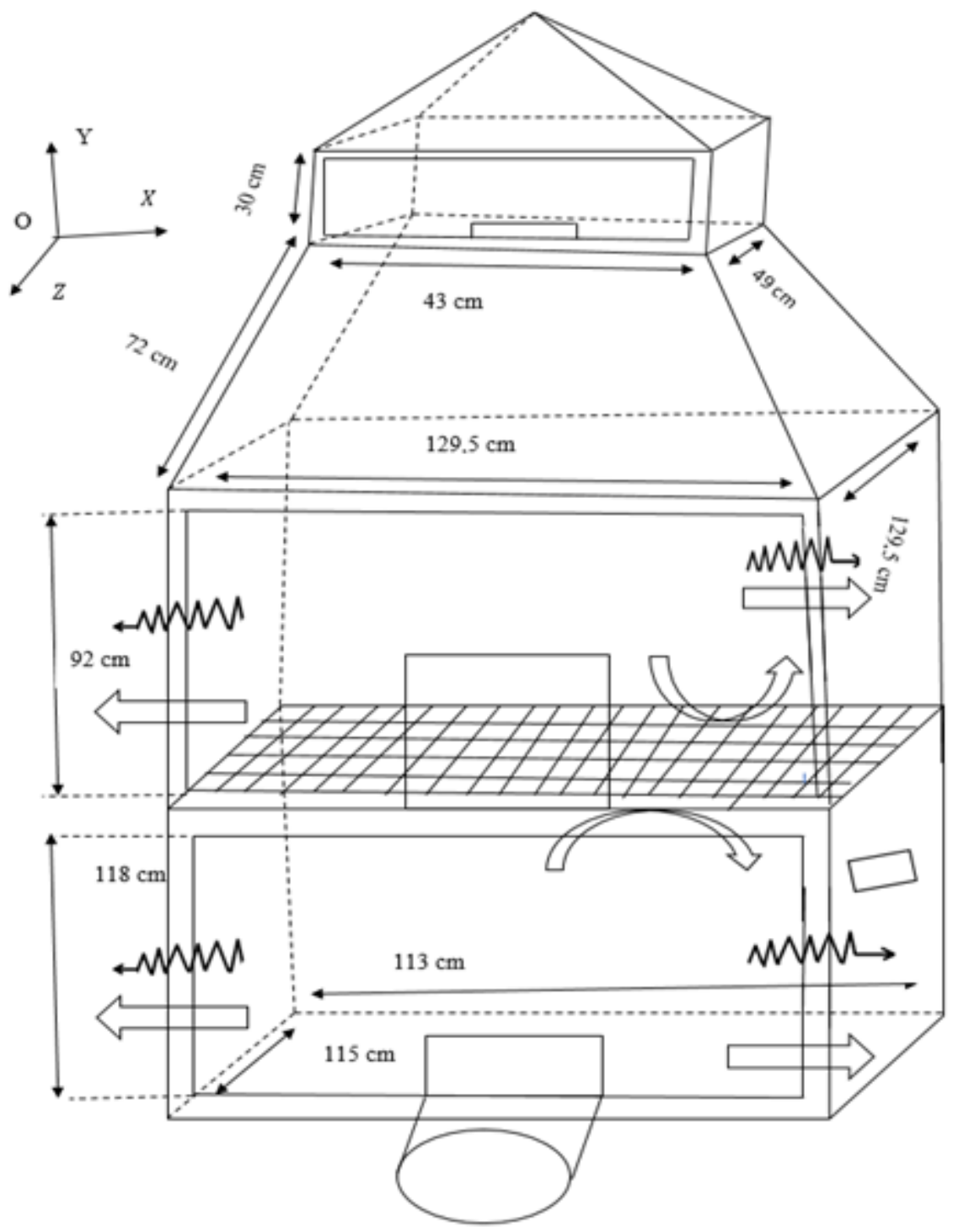

Figure 2: Diagram of the device in $3 D$

Several methods have been proposed in recent decades to model efficient heat transfer by radiation in gases participating in exchanges radiative. Among these methods, the finite volume method (MVF), introduced by Raithby and Chui [9] offers a good compromise between the precision of the results and the computation time and can be easily incorporated into computer codes dealing with radiative transfers of high-temperature gas. However, the ray effect and digital diffusion limit the use of these methods. Consequently, digital diagrams intended for practical applications have been developed by many researchers such as Chai et al. [10] and Liu and Becker [11]. MVF has been applied to regular or complex geometries. In the case of irregular geometries, the MVF was developed with the multi-block method [12]. The "body fitted coordinates" technique, used by Chui and Raithby [13], is sometimes difficult to implement in a few geometric configurations. The finite element-based finite volume method (MVCEF) was used by Proulx et al. [14] in the case of a monodimensional geometry. The combined finite volume method Monte Carlo (CMCFVM) [15] for two-dimensional 
irregular geometries attenuates the ray effect in the case of a medium, emissive and diffusing radiative energy in a way isotropic with an internal heat source.

\section{Experimental Measurements}

\subsection{Materials}

Measuring instruments are necessary for the various measurements to be carried out on the incinerator (Figure $3)$.

- A midi-type LOGGER GL220 Datalogger: This is a programmable device, which records individual measurement values and a series of measurements of certain physical quantities such as temperature, pressure, relative humidity. It is shown in Figure 3.a.

- Thermocouples: In our experiment, we have used type $\mathrm{K}$ thermocouples having $( \pm 0.05 \%$ of the reading value $+1.0^{\circ} \mathrm{C}$ ) uncertainties. It is shown in Figure 3.b.

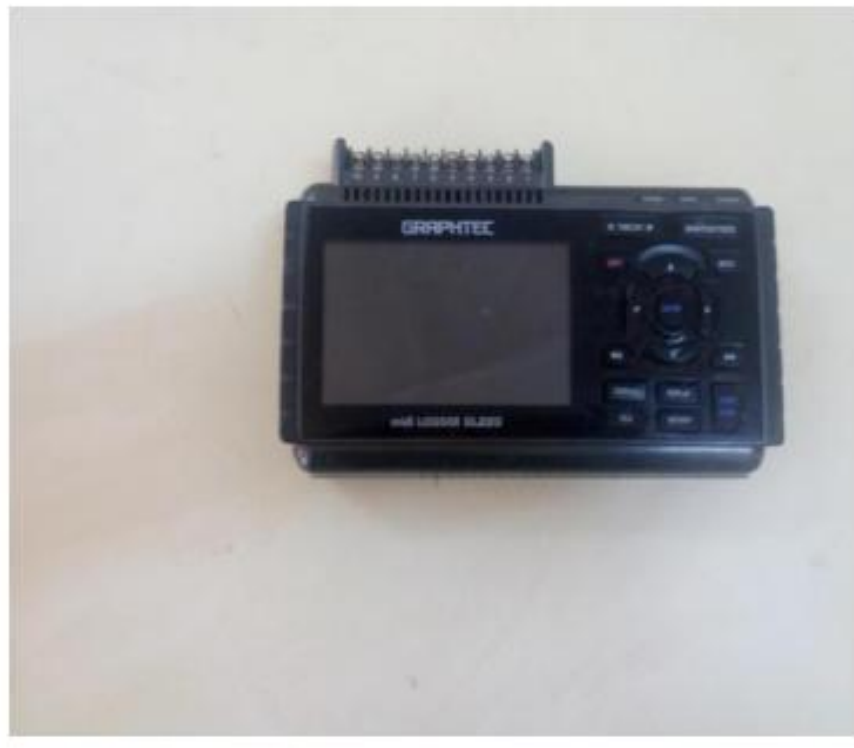

(a) Datalogger

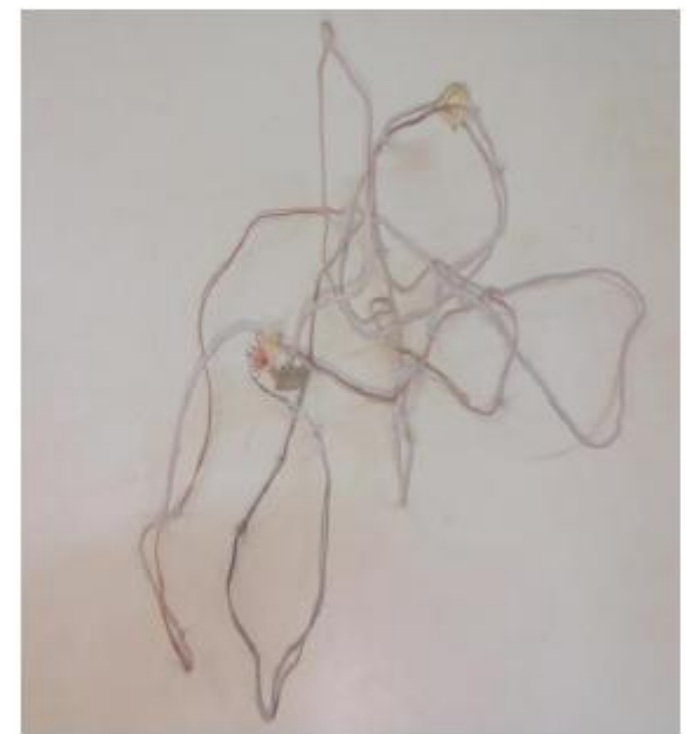

(b) thermocouple

Figure 3: Measuring instruments

\subsection{Experimental Protocol}

For the incineration test, we developed a protocol whose points are: instrumentation, paper combustion and ash extraction.

\subsubsection{Instrumentation}

Two probes (type $\mathrm{K}$ thermocouple) are placed in the combustion chamber on the fuel (papers).

These probes measure the temperature of the fuel during combustion.

These two probes are connected to the recorder (Datalogger).

Figure 4 shows the location of the thermocouples. 
IRA-International Journal of Applied Sciences

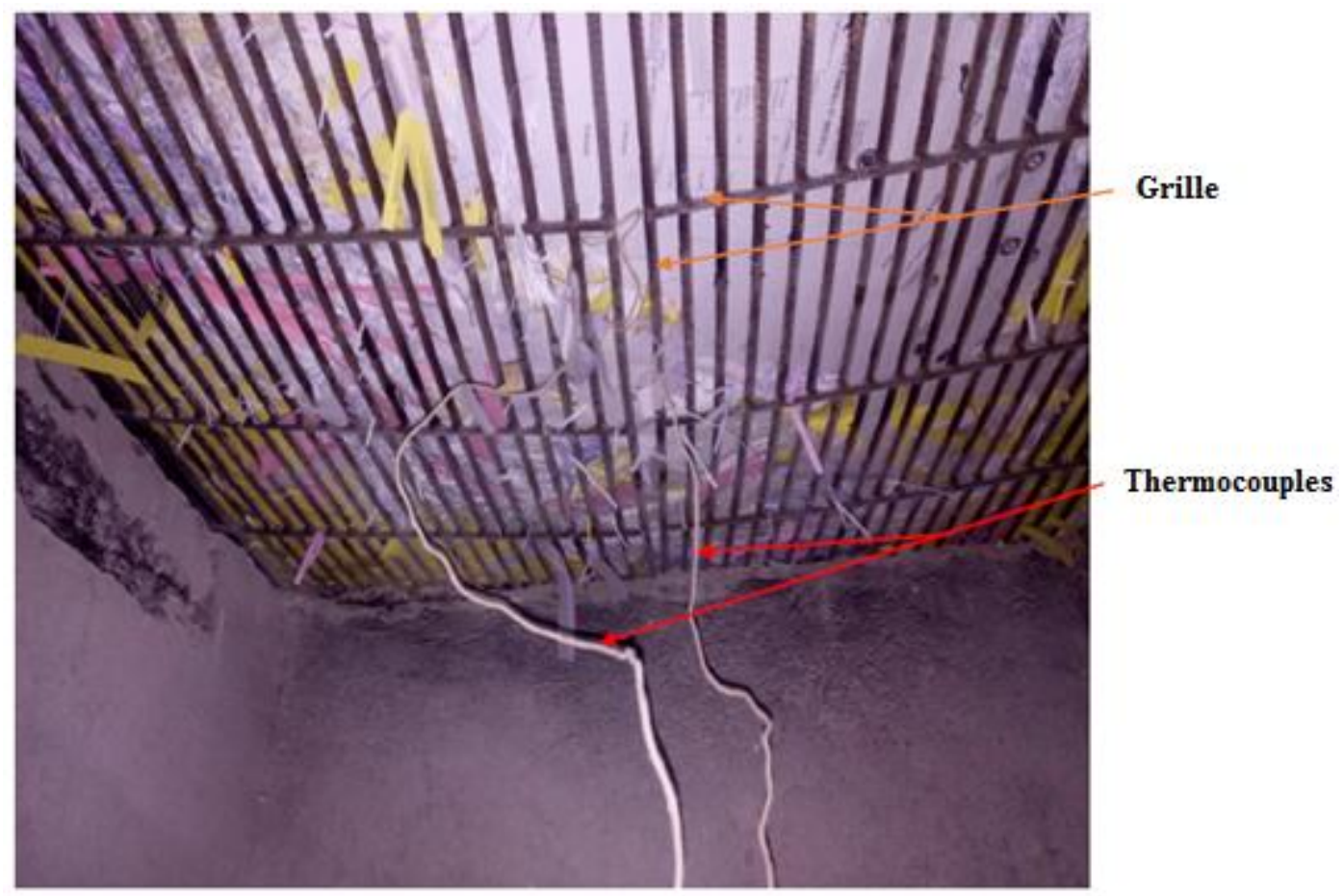

Figure 4: Location of thermocouples

\subsubsection{Combustion of Papers}

The combustion chamber is filled with paper garbage. Figure 5 shows the location of the fuel in the incinerator.

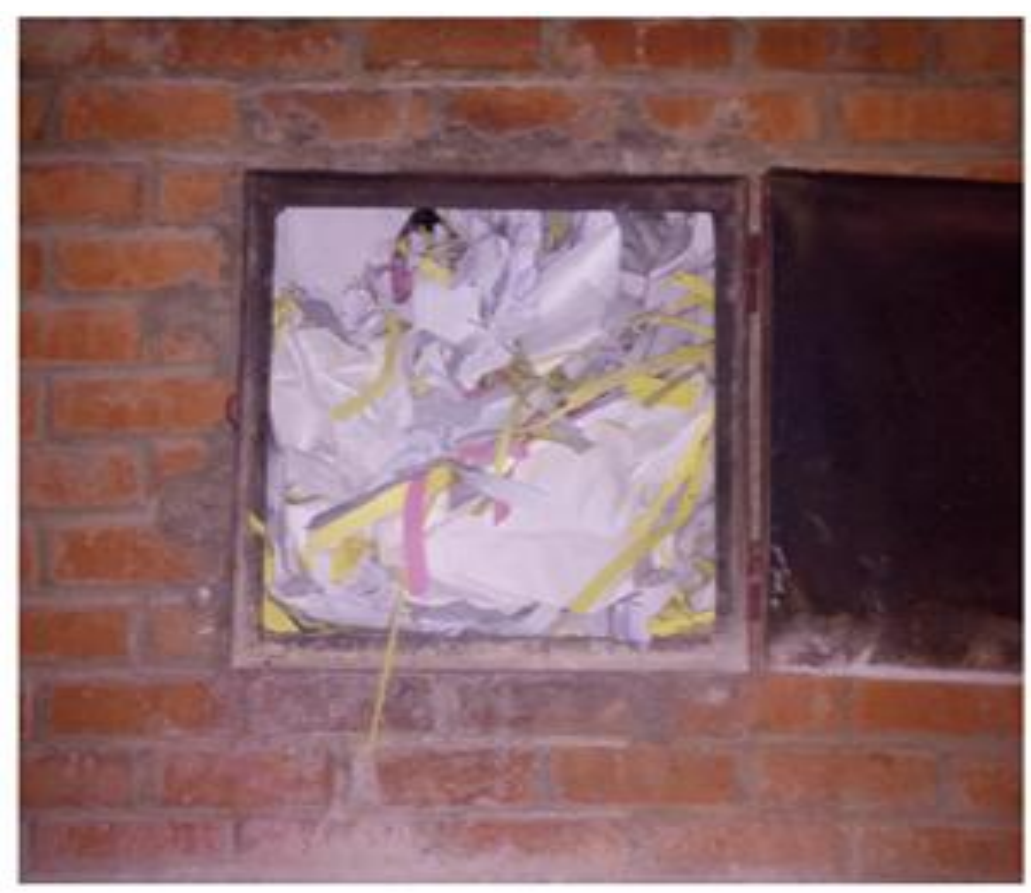

Figure 5: Location of fuel in the incinerator

After filling the combustion chamber with papers, the inlet is closed to limit heat loss.

This step is the last before igniting the fuel. 


\section{Experimental Results}

The experience took place during the month of December 2019 and lasted 10 hours (from 7:00 p.m. to 5:00 a.m.). It should be noted that during the measurements, errors were made, especially in the use of thermocouples: error in the location of a thermocouple. Thus, we were able to exploit data from a single thermocouple.

We now present in Figure 6 the overview of the combustion chamber during incineration.

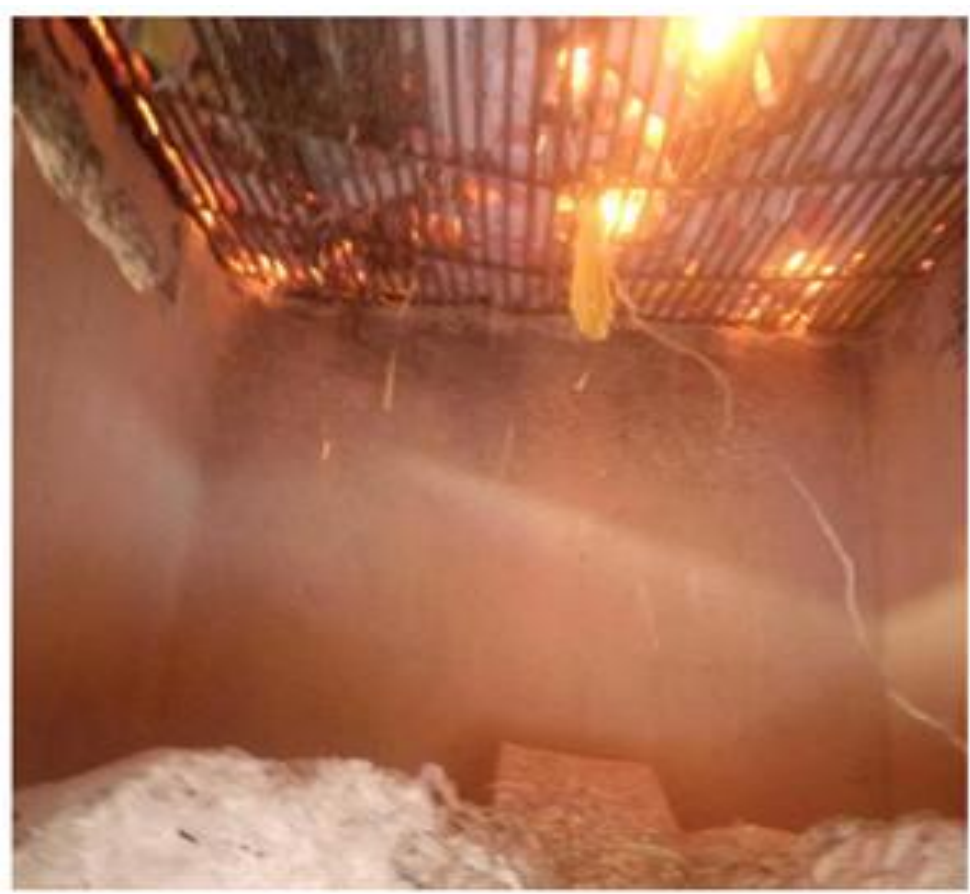

Figure 6: Overview of the combustion chamber during incineration

Once combustion begins, this garbage is first heated, and then dried before being burned. We note that the paper burns with a yellow and illuminating flame by releasing heat: The reaction is said to be exothermic. Burning paper produces black smoke which escapes outward through the chimney. The ashes produced fall to the level of the ashtray located just below the combustion chamber.

Figure 7 shows the appearance of the paper ash produced.

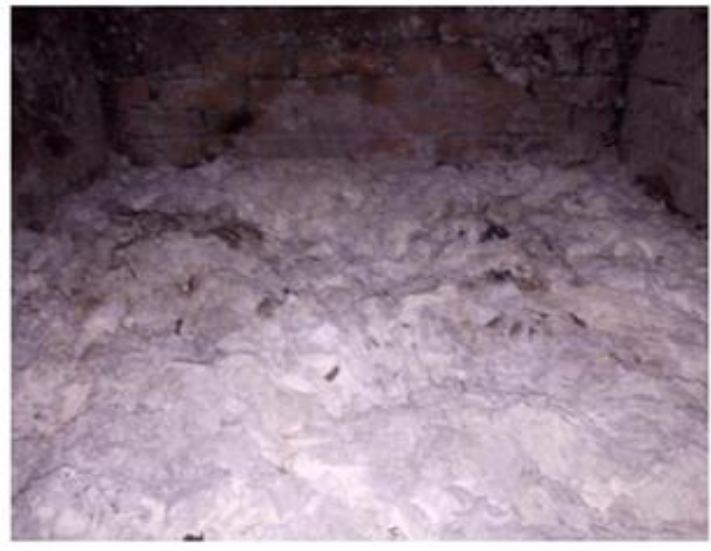

Figure 7: Appearance of paper ashes 
Paper ashes have a white color. They can be developed in the agricultural field by their use as fertilizer. In this case, they can be spread on agricultural soils or incorporated into compost [16]. At the end of the combustion, these ashes will be buried in a pit (Figure 1).

Figure 8 shows the change in the temperature of the combustion environment over time.

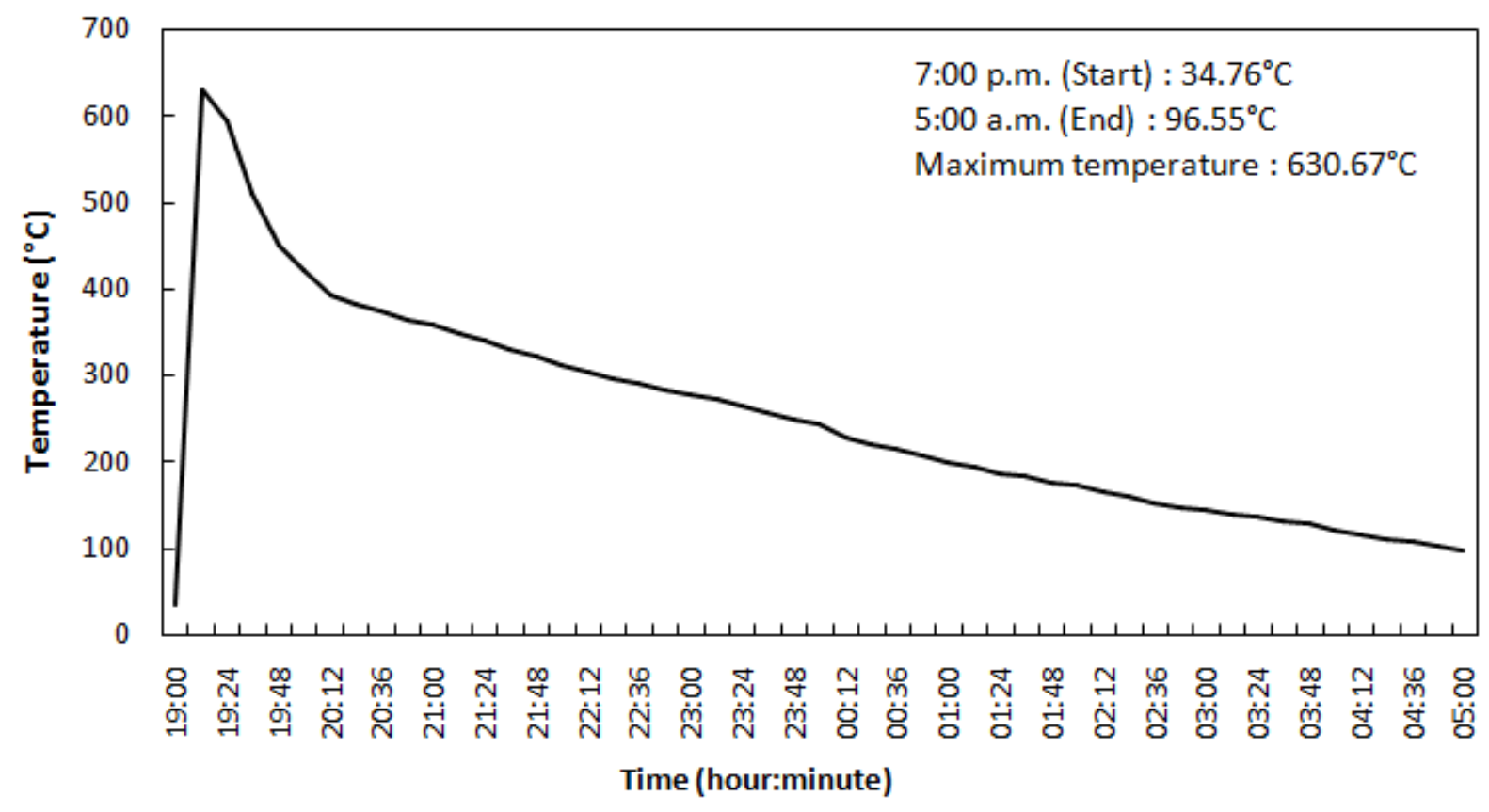

Figure 8: Evolution of the temperature of the combustion environment

In Figure 8, we observe from the start of combustion (from 7:00 p.m. to 7:12 p.m.), a sharp rise in the temperature of the combustion environment from $34.77{ }^{\circ} \mathrm{C}$ to $630.67{ }^{\circ} \mathrm{C}$. From this value, there follows a sudden decrease in temperature between $19: 12$ and $20: 12$ (from $630.67{ }^{\circ} \mathrm{C}$ to $393.40{ }^{\circ} \mathrm{C}$ ). From 8:12 p.m. to 5:00 a.m., the temperature decreases almost linearly with values ranging from $393.40{ }^{\circ} \mathrm{C}$ to $96.55{ }^{\circ} \mathrm{C}$. The sudden increase in the temperature of the combustion environment is explained by the ignition of the papers which announces the start of an exothermic reaction. The subsequent decrease in temperature is due to the decrease in the amount of paper to be burnt over time. The internal walls of the chamber store and then return heat to the combustion environment. This limits heat loss in the combustion chamber.

\section{Conclusion}

In this work, we presented an incinerator used for the combustion of paper garbage produced at the University Press of Ouagadougou. This device is built on the basis of terracotta bricks which is an eco-friendly material. At the end of the experimental study, the results show that this device is very useful in that it allows the incineration of paper garbage produced by the printing press. As a result, this device has an environmental advantage because its use promotes better management of paper waste. In addition, the paper ash produced can be used in agriculture by using it as a fertilizer. This, therefore, constitutes an additional interest beyond the preservation of the environment.

\section{References}

[1]. M. Maes, La maîtrise des déchets industriels. Ed. P. Johanet S.A, 1994.

[2]. L. Haeusler, A. G. Moro-Goubely, G. Berthoin, DECHETS, ADEME, 2014.

[3]. J. P. Camard et A. Franconi, L'incinération des déchets en Île-de-France : Considérations environnementales et sanitaires, IAURIF, 2005.

[4]. Claire de Siebenthal, Traitement et valorisation des déchets ménagers par incinération ou pyrolyse, Travail de Bachelor, Suisse, 2018. 
[5]. Syndicat national du traitement et de la Valorisation des Déchets Urbains et assimilés (SVDU), le livre blanc de l'incinération, France, 2013.

[6]. J. P. Camard et A. Franconi, L'incinération des déchets en Île-de-France : Considérations environnementales et sanitaires, Institut d'Aménagement et d'Urbanisme de la Région d'Île-de-France, 2005.

[7]. Commission Européenne, Incinération des déchets, Document de référence sur les meilleures techniques disponibles, 2006.

[8]. Y. Menard, Modélisation de l'incinération sur grille d'ordures ménagères et approche thermodynamique du comportement des métaux lourds, Thèse de Doctorat, Lorraine, 2003.

[9]. G. B. Raithby et E. H. Chui, A finite volume method for predicting a radiant heat transfer in enclosures with participating media, J. Heat Transfer, Vol. 112, pp. 415-423, 1990.

[10]. Chai, J. C., Lee, H. S., et Patankar, S. V., Finite-Volume Method for Radiation Heat Transfer, Journal of Thermophysics and Heat Transfer, Vol. 8, pp. 419-25, 1994.

[11]. F. Liu, H. A. Becker et A. Pollard, Spatial differencing schemes of the discrete ordinates method, Numerical Heat Transfer, Part B, 30: 23-43, 1996.

[12]. J. C. Chai et J. P. Moder, Spatial-multiblock procedure for radiation heat transfer, Numerical Heat Transfer, Part B, Vol. 31, pp. 277-93, 1997.

[13]. E. H. Chui et G. D. Raithby, Computation of radiant heat transfer on a non-orthogonal mesh using the finite volume method, Numerical Heat Transfer, Part B, Vol. 23, pp. 269-88, 1993.

[14]. C. Proulx, D. R. Rousse, R. Vaillon et J.-F. Sacadura, Rayonnement collimaté sur une couche plane semi transparente: incidence oblique du faisceau, V Colloque Interuniversitaire Franco-Québécois, Thermique des Systèmes. Lyon, France, 28-30, Mai 2001.

[15]. S. W. Baek, D. Y. Byun et S.J. Kang, The combined Monte Carlo and finite volume method for radiation in a two-dimensional irregular geometry, Int. J. Heat Mass Transfer, Vol. 43, pp. 2337-44, 2000.

[16]. D. Boulday et F. Marcovecchio, Valorisation des cendres issues de la combustion de biomasse, Revue des gisements et des procédés associés, 91 p., n¹4-0913/1A, 2016. 